\title{
THE RELATIONSHIP BETWEEN THE GROSS EFFICIENCY AND THE ABILITY TO REPEAT THE GIVEN PRESSURE FORCE IN TRAINED CYCLISTS
}

original paper

( ) University School of Physical Education in Wroclaw

DOI: https://doi.org/10.5114/hm.2019.79217

\section{RAFAL HEBISZ ${ }^{1}$, RYSZARD BLACHA ${ }^{2}$, PAULINA HEBISZ ${ }^{1}$, STEFAN SZCZEPAN ${ }^{2}$}

${ }^{1}$ Department of Physiology and Biochemistry, University School of Physical Education in Wroclaw, Wroclaw, Poland

${ }^{2}$ Department of Swimming, University School of Physical Education in Wroclaw, Wroclaw, Poland

\section{ABSTRACT}

Purpose. The research aim was to determine the relationship between gross efficiency (E) and the ability to repeat the given pressure force (ARGPF).

Methods. A group of 23 road cyclists performed an incremental exercise test on a cycle ergometer and a repeated isometric force test (RIFT) with lower and upper limbs. E was calculated on the basis of the estimated energy expenditure (EE) during the last 30 seconds of the submaximal work with the loads of E-100W, E-150W, E-200W, E-250W, E-300W. During RIFT, carried out on a kinesthesiometer with strain gauges, the subjects performed pressures with the force of $10 \mathrm{~kg}$ with upper limbs and $20 \mathrm{~kg}$ with lower limbs. RIFT was performed immediately before and after the incremental test; the data served to express ARGPF by means of the repeated given pressure force (RGPF) value.

Results. Post-exercise RGPF for the left lower limb significantly correlated with $\mathrm{E}$ at all incremental test loads $(r$ : 0.64, 0.72, 0.7, 0.63, 0.62, respectively, for $100 \mathrm{~W}, 150 \mathrm{~W}, 200 \mathrm{~W}, 250 \mathrm{~W}$, and $300 \mathrm{~W})$. Pre-exercise RGPF for the left upper limb significantly correlated with $\mathrm{E}$ at $100 \mathrm{~W}, 150 \mathrm{~W}$, and $200 \mathrm{~W}$ loads ( $r: 0.68,0.72,0.62$, respectively). Both RGPF for limbs and $\mathrm{E}$ positively and statistically significantly correlated with the cyclists' age.

Conclusions. Road cyclists with higher E presented greater variability of the repeated pressure force of the left limbs. Both characteristics show a strong relationship with the cyclists' age, which may indicate that their development depends on training experience.

Key words: gross efficiency, efficiency, ability to repeat, pressure force

\section{Introduction}

The main determinant of cycling efficiency is neuromuscular coordination [1, 2], which constitutes the ability to initiate and control voluntary movements and body posture by the central nervous system structures [3]. The efficiency of the body posture and voluntary movements control is mainly attributed to the pyramidal tracts $[4,5]$. Stimulation of alpha motoneurons activates the appropriate number and size of motor units and is used to control pressure force [6, 7]. Apart from the pyramidal tracts, the extrapyramidal system centres and cerebellum [3, 8, 9] are involved in movement control and modification owing to the reception of the afferent stimuli [9].
One of the main factors that determine sporting achievements in cycling is work efficiency [10]. The most popular way to evaluate it is to calculate gross efficiency performance, i.e. the efficiency of the chemical energy transformation into the mechanical energy during physical exercise $[11,12]$. Initially, comparative research showed that training and competition experience did not significantly differentiate amateur cyclists in terms of work efficiency on a cycle ergometer [13]. However, subsequent studies showed that the level of work efficiency correlated negatively with the maximum oxygen uptake $\left(\mathrm{VO}_{2} \max \right)$ in elite cyclists [14]. This relationship among professional cyclists is confirmed by the fact that a two-time world cycling champion achieved $\mathrm{VO}_{2}$ max at the level of ca.

Correspondence address: Stefan Szczepan, Department of Swimming, University School of Physical Education in Wroclaw, al. I.J. Paderewskiego 35, 51-612 Wroclaw, Poland, e-mail: stefan.szczepan@awf.wroc.pl

Received: July 6, 2018

Accepted for publication: October 17, 2018

Citation: Hebisz R, Blacha R, Hebisz P, Szczepan S. The relationship between the gross efficiency and the ability to repeat the given pressure force in trained cyclists. Hum Mov. 2019;20(1):48-54; doi: https://doi.org/10.5114/hm.2019.79217. 
$70 \mathrm{ml} \cdot \mathrm{kg}^{-1} \cdot \mathrm{min}^{-1}$ [15]. Because of the high gross efficiency value (ca. $25 \%$ ), cyclists with a relatively lower level of $\mathrm{VO}_{2}$ max are able to compete effectively among professionals [16]. In addition, the research by Hopker et al. [17] demonstrated that the endurance training improved work efficiency in trained cyclists. The size of changes depends on the volume and intensity of training. In addition, work efficiency develops in trained cyclists as a result of strength [18] and interval trainings with high-frequency of movements [19]. It was shown that in cyclists [20] and non-training people [21], the efficiency of work on a cycle ergometer depended on the content of type I muscle fibres in the vastus lateralis muscle. In professional cyclists, the increase in cadence in the range of 60-120 rev $\cdot \mathrm{min}^{-1}$, with a small external load, causes a decrease in the gross efficiency [22]. However, at high loads (80-90\% $\mathrm{VO}_{2} \max$ ), the increase in cadence leads to an improvement of the delta efficiency [23] and gross efficiency [24] in elite cyclists. Although the assessment of work efficiency on a cycloergometer is easy to perform, its use is limited to analyses carried out during performance tests. That is why it seems useful to search for indirect gross efficiency assessment methods that could be used in everyday life practice training.

It is believed that work efficiency depends on muscular coordination, i.e. minimizing muscle tension [25] through cooperation between synergistic and antagonistic muscle groups in both limbs [26, 27] and eliminating unnecessary muscle contractions [26], while maintaining body balance [25]. In cycling, movement is repeated many times [26]. If many of these movements are inaccurate, i.e. different from the above description, the amount of internal work and energy expenditure increases [26]. Perhaps the ability to coordinate cycling can be assessed with the accuracy of repeated pressures. So it seems interesting whether there is a relationship between muscular coordination, understood as the ability to repeat the given pressure force (ARGPF), and the gross efficiency. ARGPF may be dependent on the hippocampus performance, in which changes caused by endurance activity occur and influence the learning ability [28]. The ability to repeat the force generated by the upper and lower limb muscles in a stable position may also depend on other central nervous system structures [29, 30], which was discussed at the beginning of the Introduction. However, there is no information in the available literature about the relationship between ARGPF and work efficiency in cyclists with diverse performance levels. It was assumed that ARGPF in lower and upper limbs would positively correlate with gross efficiency in submaximal efforts.

The aim of the research was to determine the relationship between the gross efficiency and ARGPF.

\section{Material and methods}

\section{Examined group}

Overall, 23 young healthy and physically active cyclists (juniors and U23) with a varied level of fitness (well-trained, highly-trained, and elite-class) took part in the study. All subjects were characterized by the domination of right limbs. Table 1 shows selected parameters of the examined group.

Each cyclist qualified for the tests had at least 2 years of training experience. They took part in cycling competitions at least for 20 days a year and covered 7000 $25000 \mathrm{~km}$ annually, including $83-88 \%$ with intensity below the lactate threshold power, $8-12 \%$ between the lactate threshold power and maximum aerobic power (Pmax), 3-5\% above Pmax.

\section{Study design}

During the 48 hours before the exercise test start, the subjects did not perform any heavy physical effort. Each participant underwent an incremental exercise test on a cycle ergometer and a repeated isometric force test (RIFT) for the lower and upper limbs. The RIFT test was carried out 10 minutes before the incremental test start and 5 minutes after its completion.

Table 1. Anthropological parameters and aerobic capacity of the examined cyclists

\begin{tabular}{lcccc}
\cline { 2 - 4 } & Mean value & $S D$ & Min & Max \\
\hline Age & 18.7 & 1.5 & 16.6 & 23 \\
Body height $(\mathrm{m})$ & 1.77 & 6.94 & 1.61 & 1.92 \\
Body mass $(\mathrm{kg})$ & 67.8 & 6.6 & 57.4 & 79.2 \\
$\mathrm{VO}_{2} \max \left(\mathrm{ml} \cdot \mathrm{kg}^{-1} \cdot \mathrm{min}^{-1}\right)$ & 64.2 & 6.4 & 52 & 80.8 \\
Pmax $(\mathrm{W})$ & 365.2 & 31.1 & 308.3 & 425 \\
Pmax $\left(\mathrm{W} \cdot \mathrm{kg}^{-1}\right)$ & 5.42 & 0.52 & 4.55 & 6.37 \\
\hline
\end{tabular}

$S D$ - standard deviation, Min - minimum value of the parameter in the examined group, Max - maximum value of the parameter in the examined group, $\mathrm{VO}_{2} \mathrm{max}$ - maximum oxygen uptake, Pmax - maximum aerobic power 
R. Hebisz, R. Blacha, P. Hebisz, S. Szczepan, Ability to repeat the given pressure force

\section{Testing protocols}

\section{Anthropometric measurements}

The subjects' weight and height were measured with a Radwag WPT200.O weighing machine (Radwag, Poland). The range and accuracy of the body mass measurement was $2-200 \mathrm{~kg}$ and $100 \mathrm{~g}$. The range and accuracy of body height measurement was 1-2 m and $0.5 \mathrm{~cm}$.

\section{Analysis of the volume of training loads used}

Among the cyclists qualified to participate in the study, the overall route was calculated $\left(\mathrm{S}_{\text {tot }}\right)$ covered during the cycling training within the 2 years preceding the experiment. The calculations were made on the basis of training records collected on individual Internet accounts.

\section{Incremental test}

The exercise test was carried out on a Lode Excalibur Sport cycle ergometer (Lode B.V. Groningen, the Netherlands), calibrated before the study. The test started with the load of $50 \mathrm{~W}$; the load was increased every 3 minutes by $50 \mathrm{~W}$, until the subject refused to continue. When the participant was unable to complete an entire 3 -minute stage, $0.28 \mathrm{~W}$ was subtracted for each missing second from the work rate for that stage. The highest power output determined in the incremental exercise test was taken as the measure of Pmax.

Respiratory function was also measured during the test. The cyclist wore a mask connected to a Quark gas analyser (Cosmed, Milan, Italy). The gas analyser was calibrated before the use with a reference gas mixture of carbon dioxide (5\%), oxygen (16\%), and nitrogen (79\%). Tidal air was analysed on a breath-by-breath basis to determine oxygen uptake, carbon dioxide excretion, and minute pulmonary ventilation. $\mathrm{VO}_{2} \max$ calculation was based on the composition of the expired air and minute ventilation. The measures were averaged in 30-second intervals.

Pmax and $\mathrm{VO}_{2} \max$ were calculated in relation to body mass.

The gross efficiency was determined for the last 30 seconds of the submaximal work with loads of $100 \mathrm{~W}$ (E-100W), $150 \mathrm{~W}$ (E-150W), $200 \mathrm{~W}$ (E-200W), $250 \mathrm{~W}$ (E-250W), and $300 \mathrm{~W}(\mathrm{E}-300 \mathrm{~W})$ on the basis of the following formula:

$$
\mathrm{E}=\mathrm{W} \cdot \mathrm{EE}^{-1} \cdot 100 \%
$$

where: E - gross efficiency, W - work rate, EE - energy expenditure.

Work rate was calculated as the product of the given power and time for which the data were analysed. Energy expenditure was determined by the software provided by the respiratory gas analyser manufacturer with the use of the protocol of the indirect calorimetric method.

\section{Repeated isometric force test}

RIFT was performed on a dedicated kinesthesiometer, applied to measure the pressure force by means of strain gauges. The device enables testing sensory sensitivity related to the differentiation of the pressure force and the pressure force uniformity. The kinesthesiometer can also be used to measure the precision of the upper and lower limbs movements [31]. The values of the subsequent pressure forces determined by the force sensor are converted into electrical signals, which are then amplified, processed, and registered. Four strain gauges, which measure the pressure force, are located in the levers of the platform, used for the right and left upper limbs testing, and in the pedals of the platform, applied for the right and left lower limbs testing. The values of individual pressure forces were recorded by a computer software: Kinesthesiometer, version 1 . The measuring system was located in the dedicated chair adapted for the testing

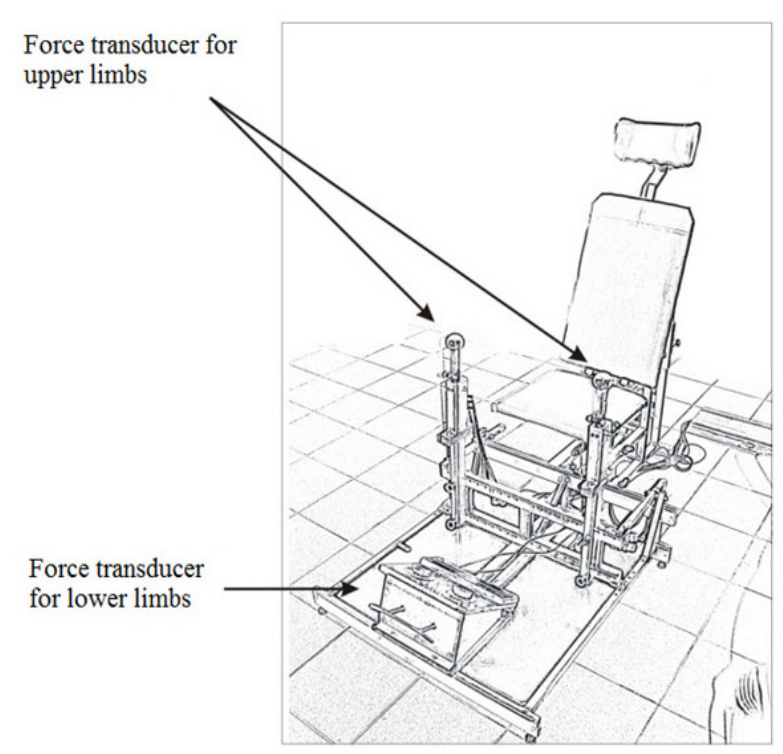

Figure 1. The kinesthesiometer for measuring the repeated isometric force of upper and lower limbs (reprinted from [31]) 
purposes (Figure 1). The device was approved for use for diagnostic purposes and entered into the Polish Patent Office register (patent number PL 213505 B1) [32].

The kinesthesiometer was calibrated before the measurement with weights of $1 \mathrm{~kg}, 5 \mathrm{~kg}$, and $10 \mathrm{~kg}$. Immediately prior to each kinesthesiometer test, the subjects performed 5 pressures with each limb, during which the obtained pressure force was displayed. The participants observed the results of the trial test on the monitor and could adjust the force used to the force specified in the main test.

The RIFT test for upper and lower limbs was performed in a sitting position, without touching the kinesthesiometer chair backrest. The lack of support made it impossible to receive skin sensation information transmitted from the exteroceptors to the cerebral cortex, which could affect the study results.

During the RIFT test for the upper limbs, the subject held the platform lever for upper limbs testing with one hand. The other hand was resting on the thigh. During the lower limb test, the feet rested on the pedal of the platform for lower limbs testing. The pedal was located obliquely to the kinesthesiometer base. During the test, arms were crossed on the chest to eliminate skin receptors stimuli transmitted to the cortex from the forearms and thighs of the subject.

RIFT consisted of 10 identical pressures with each limb, with the force equal to $10 \mathrm{~kg}(98 \mathrm{~N})$ for upper limbs and $20 \mathrm{~kg}(196 \mathrm{~N})$ for lower limbs. A break of 5 seconds took place between each pressure, during which the subject removed the limb from the pressure site. The data obtained during the RIFT test were used to express ARGPF by means of the repeated given pressure force (RGPF) value [28]. The RGPF index is based on the following formula:

$$
\mathrm{RGPF}=S D \cdot \bar{X}^{-1} \cdot 100
$$

where: RGPF - repeated given pressure force, $S D$ standard deviation of $\bar{X}, \bar{X}$-arithmetic mean of the 10 consecutive pressure forces

In this way, the pre-exercise and post-exercise values were obtained for: right upper limb (R-U-RGPF ${ }_{b}$ and R-U-RGPF ${ }_{p}$, respectively), right lower limb (R-L-RGPF and R-L-RGPF ${ }_{\mathrm{p}}$, respectively), left upper limb (L-U$\mathrm{RGPF}_{\mathrm{b}}$ and L-U-RGPF , respectively), and left lower limb (L-L-RGPF ${ }_{\mathrm{b}}$ and L-L-RGPF ${ }_{\mathrm{p}}$, respectively).

\section{Statistical data analysis}

Statistical analyses were performed with the Statistica 13.1 software (StatSoft, USA). The normality of the examined parameters distribution was checked with the W Shapiro-Wilk test. Then, the Pearson correlation coefficient was calculated for the RIFT parameters, submaximal work efficiency, $\mathrm{Pmax}, \mathrm{VO}_{2} \max$, age, body height, and body mass of the tested cyclists. Pearson's correlation was also determined for the RIFT parameters, submaximal work efficiency, and $\mathrm{S}_{\text {tot }}$ for the research group and separately for cyclists who completed and were under 19 years of age. The $p<0.05$ level was considered statistically significant [33].

\section{Ethical approval}

The research related to human use has been complied with all the relevant national regulations and institutional policies, has followed the tenets of the Declaration of Helsinki, and has been approved by the Ethics Committee for Research at the University School of Physical Education in Wroclaw.

\section{Informed consent}

Informed consent has been obtained from all individuals included in this study or their legal guardians.

\section{Results}

The R-U-RGPF $F_{\mathrm{p}}$ correlated significantly with gross efficiency at the load of $100 \mathrm{~W}$. The L-U-RGPF ${ }_{b}$ correlated significantly with gross efficiency at the load of $100 \mathrm{~W}, 150 \mathrm{~W}$, and $200 \mathrm{~W}$. In the case of R-U$\mathrm{RGPF}_{\mathrm{b}}$ and L-U-RGPF , no significant relationships were observed (Table 2).

The L-L-RGPF ${ }_{b}$ correlated significantly with gross efficiency at the load of $150 \mathrm{~W}$ and $200 \mathrm{~W}$. The L-L$\mathrm{RGPF}_{\mathrm{p}}$ correlated with gross efficiency at all loads applied. In the case of the R-L-RGPF, no significant relationship was observed (Table 3).

Body height correlated significantly with the R-U$\operatorname{RGPF}_{\mathrm{p}}(r=-0.43)$. The age of the subjects correlated significantly with the R-U-RGPF ${ }_{\mathrm{b}}$ and R-U-RGPF $(r=$ 0.45 and $r=0.44$, respectively), the L-U-RGPF ${ }_{\mathrm{b}}$ and L-U-RGPF $(r=0.54$ and $r=0.43$, respectively) and the L-L-RGPF $(r=0.56)$. There were also statistically significant correlations between age and gross efficiency at the loads of $150 \mathrm{~W}(r=0.52), 200 \mathrm{~W}(r=0.58)$, $250 \mathrm{~W}(r=0.49)$, and $300 \mathrm{~W}(r=0.54)$, and between $\mathrm{VO}_{2}$ max and gross efficiency at the loads of $200 \mathrm{~W}(r=$ $-0.6), 250 \mathrm{~W}(r=-0.53)$, and $300 \mathrm{~W}(r=-0.46)$. For Pmax, no significant correlations were observed.

In the analysis performed in the whole research group, $S_{\text {tot }}$ correlated statistically significantly with gross efficiency for all submaximal loads under analysis $(r=0.52$ at $100 \mathrm{~W}, r=0.83$ at $150 \mathrm{~W}, r=0.9$ at 


\section{HUMAN MOVEMENT}

R. Hebisz, R. Blacha, P. Hebisz, S. Szczepan, Ability to repeat the given pressure force

$200 \mathrm{~W}, r=0.81$ at $250 \mathrm{~W}, r=0.74$ at $300 \mathrm{~W}$ ) and with $\mathrm{L}-\mathrm{L}-\mathrm{RGPF}_{\mathrm{b}}(r=0.6)$. In the analysis performed among competitors who were under 19 years of age, $\mathrm{S}_{\text {tot }}$ correlated statistically significantly only with E-200W $(r=$ $0.61)$, E-250W ( $r=0.61)$, and E-300W ( $r=0.73)$. In the analysis carried out among 19-year-old subjects, $\mathrm{S}_{\text {tot }}$ correlated statistically significantly with E-150W $(r=0.86)$, E-200W $(r=0.89)$, E-250W $(r=0.71)$, and with L-L-RGPF ${ }_{\mathrm{b}}(r=0.58)$, L-L-RGPF $(r=0.66)$ and L-U-RGPF ${ }_{\mathrm{b}}(r=0.55)$.

\section{Discussion}

The results of the research confirmed an inverse correlation between $\mathrm{VO}_{2}$ max and gross efficiency in trained cyclists.

A novelty of our research results is the information that the discussed relationship occurs in a wide group of cyclists in terms of the $\mathrm{VO}_{2}$ max value. Its minimum and maximum equalled 52 and $80.8 \mathrm{ml} \cdot \mathrm{kg}^{-1} \cdot \mathrm{min}^{-}$ ${ }^{1}$, respectively, and the standard deviation was 6.4. Previously, similar data for cyclists were obtained by Hopker et al. [14] and Lucia et al. [24]. However, these two studies were carried out in groups that were homogeneous in performance. Hopker et al. [14] assessed work efficiency among well-trained $\left(\mathrm{VO}_{2} \max : 59.5 \pm\right.$ $3.8 \mathrm{ml} \cdot \mathrm{kg}^{-1} \cdot \mathrm{min}^{-1}$ ), and Lucia et al. [24] among elite professional cyclists $\left(\mathrm{VO}_{2}\right.$ max: $\left.72 \pm 1.8 \mathrm{ml} \cdot \mathrm{kg}^{-1} \cdot \mathrm{min}^{-1}\right)$. Until now, it has been believed that among professional cyclists, similar gross efficiency allows to compensate for slightly lower efficiency $\mathrm{VO}_{2}$ max values [14]. In this way, the phenomenon of winning the world champion title twice by a cyclist with $\mathrm{VO}_{2}$ max below $70 \mathrm{ml}$. $\mathrm{kg}^{-1} \cdot \mathrm{min}^{-1}$ was explained [24]. Our results indicate that this mechanism allows to partially compensate for the value of $\mathrm{VO}_{2}$ max also among competitors with significantly lower cardiorespiratory capacity.

In the presented own study, the gross efficiency correlated with the RGPF value. This means a negative verification of the adopted hypothesis because it indicates an inverse correlation between gross efficiency and the ARGPF performance. High-performance athletes were characterized by greater variability of RGPF, especially in the left upper limb during the pre-exercise test and in the lower limb both in the pre- and postexercise tests. We have also shown that both the gross efficiency and RGPF of the limbs depend on the subjects' age and the $S_{\text {tot }}$ of the cycling training in the period of 2 years preceding the tests. These data support the results of other authors' research, indicating that the gross efficiency develops through aerobic training [14, 17], which may be related to the impact of physical activity and specific movement forms on the enhancement of the precision and ease of movement [34]. Therefore, the own data and the results achieved by other authors indicate that gross efficiency and RGPF are well-trained abilities. At the same time, our results prove that obtaining high gross efficiency

Table 2. Correlations between the repeated given pressure force value and the gross efficiency for submaximal work in the incremental test (upper limbs)

\begin{tabular}{lccccc} 
& E-100W (\%) & E-150W (\%) & E-200W (\%) & E-250W (\%) & E-300W (\%) \\
\hline R-U-RGPF $_{b}(\mathrm{~N})$ & 0.23 & 0.39 & 0.34 & 0.06 & -0.09 \\
R-U-RGPF $_{\mathrm{p}}(\mathrm{N})$ & $0.58^{*}$ & 0.45 & 0.36 & 0.18 & 0.29 \\
L-U-RGPF $_{\mathrm{b}}(\mathrm{N})$ & $0.68^{*}$ & $0.72^{*}$ & $0.62^{*}$ & 0.33 & 0.30 \\
L-U-RGPF $_{\mathrm{p}}(\mathrm{N})$ & 0.35 & 0.42 & 0.41 & 0.12 & 0.01 \\
\hline
\end{tabular}

E - gross efficiency at the loads of 100, 150, 200, 250, and $300 \mathrm{~W}, \mathrm{R}-\mathrm{U}$ - right upper limb, L-U - left upper limb, $\mathrm{RGPF}$ - repeated given pressure force, $\mathrm{b}$ - before the incremental test, $\mathrm{p}$ - after the incremental test, ${ }^{*} p<0.05$

Table 3. Correlations between the repeated given pressure force value and the gross efficiency for submaximal work in the incremental test (lower limbs)

\begin{tabular}{lccccc} 
& E-100W (\%) & E-150W (\%) & E-200W (\%) & E-250W (\%) & E-300W (\%) \\
\hline R-L-RGPF $_{\mathrm{b}}(\mathrm{N})$ & 0.25 & 0.38 & 0.23 & 0.21 & 0.15 \\
R-L-RGPF $_{\mathrm{p}}(\mathrm{N})$ & 0.09 & 0.06 & 0.02 & 0.04 & 0.07 \\
L-L-RGPF $_{\mathrm{b}}(\mathrm{N})$ & 0.47 & $0.69^{*}$ & $0.52^{*}$ & 0.21 & 0.34 \\
L-L-RGPF $_{\mathrm{p}}(\mathrm{N})$ & $0.64^{*}$ & $0.72^{*}$ & $0.70^{*}$ & $0.63^{*}$ & $0.62^{*}$ \\
\hline
\end{tabular}

E - gross efficiency at the loads of 100, 150, 200, 250, and $300 \mathrm{~W}, \mathrm{R}-\mathrm{L}$ - right lower limb, L-L - left lower limb, RGPF - repeated given pressure force, $\mathrm{b}$ - before the incremental test, $\mathrm{p}$ - after the incremental test,

${ }^{*} p<0.05$ 
may be accompanied by relatively large RGPF values for the left limbs. Such regularity may be related to lateralization. In most populations, right limbs play the dominant role [35], while the right hemisphere is responsible for correcting movements [36] and registers information mainly from proprioceptors of the left, non-dominant limb [37, 38]. Thus, high variation of the pressure force within the isolated work of the left limbs may indicate a developed ability to adjust the pressure force.

The obtained results may be useful for the development of simple tests allowing the work efficiency evaluation. At present, energy expenditure [39] and mechanical efficiency of work [40] are assessed mainly with indirect calorimetric methods. However, this evaluation method is not routinely used during training owing to its complex procedure. It is believed that the exercise heart rate during the stabilization phase reflects the energetic cost of work [41]. However, the energy cost is not the only factor influencing the exercise heart rate, which is regulated by the activity of the autonomic nervous system [42] and cardiovascular fitness [43]. In contrast to the above methods, a simple and indirect test for the repeated pressure force, lasting a few minutes, would allow easy assessment of work efficiency in everyday training practice. It seems desirable by trainers and athletes because of the high importance assigned to work performance in endurance competitions.

\section{Conclusions}

Cyclists with higher gross efficiency are characterized by greater variability of the RGPF of the left limbs. Both of these characteristics show a strong relationship with the age of cyclists, which may indicate that their development depends on the training experience. We believe that the observed relationships may be related to the lateralization of the cerebral hemispheres in terms of its functions.

\section{Disclosure statement}

No author has any financial interest or received any financial benefit from this research.

\section{Conflict of interest}

The authors state no conflict of interest.

\section{References}

1. Blake OM, Wakeling JM. Muscle coordination limits efficiency and power output of human limb movement under a wide range of mechanical demands. J Neuro- physiol. 2015;114(6):3283-3295; doi: 10.1152/jn.00765. 2015.

2. Wakeling JM, Blake OM, Chan HK. Muscle coordination is key to the power output and mechanical efficiency of limb movements. J Exp Biol. 2010;213(3):487-492; doi: $10.1242 /$ jeb.036236.

3. Heckman CJ, Enoka RM. Motor unit. Compr Physiol. 2012;2(4):2629-2682; doi: 10.1002/cphy.c100087.

4. Canedo A. Primary motor cortex influences on the descending and ascending systems. Prog Neurobiol. 1997; 51(3):287-335; doi: 10.1016/S0301-0082(96)00058-5.

5. Guillery RW, Sherman SM. The thalamus as a monitor ofmotor outputs. Phil Trans RSocLondB. 2002;357(1428): 1809-1821; doi: 10.1098/rstb.2002.1171.

6. Westerblad H, Bruton JD, Katz A. Skeletal muscle: energy metabolism, fiber types, fatigue and adaptability. Exp Cell Res. 2010;316(18):3093-3099; doi: 10.1016/j. yexcr.2010.05.019.

7. Monster AW, Chan H. Isometric force production by motor units of extensor digitorum communis muscle in man. J Neurophysiol. 1977;40(6):1432-1443; doi: 10.1152/jn.1977.40.6.1432.

8. Manto M, Bower JM, Conforto AB, Delgado-García JM, da Guarda SNF, Gerwig M, et al. Consensus paper: roles of the cerebellum in motor control - the diversity of ideas on cerebellar involvement in movement. Cerebellum. 2012;11(2):457-487; doi: 10.1007/s12311-0110331-9.

9. Carp JS, Wolpaw JR. Motor neurons and spinal control ofmovement.eLS.2010; doi:10.1002/9780470015902. a0000156.pub2.

10. Coyle EF. Physiological determinants of endurance exercise performance. J Sci Med Sport. 1999;2(3):181-189; doi: 10.1016/S1440-2440(99)80172-8.

11. Zatoń M, Michalik K. Effects of interval training-based glycolytic capacity on physical fitness in recreational long-distance runners. Hum Mov. 2016;16(2):71-77; doi: 10.1515/humo-2015-0029.

12. Hopker J, Passfield L, Coleman D, Jobson S, Edwards $\mathrm{L}$, Carter H. The effects of training on gross efficiency in cycling: a review. Int J Sports Med. 2009;30(12):845850; doi: 10.1055/s-0029-1237712.

13. Marsh AP, Martin PE, Foley KO. Effect of cadence, cycling experience, and aerobic power on delta efficiency during cycling. Med Sci Sports Exerc. 2000;32(9):1630 -1634; doi: 10.1097/00005768-200009000-00017.

14. Hopker J, Coleman D, Jobson SA, Passfield L. Inverse relationship between $\mathrm{VO}_{2}$ max and gross efficiency. Int J Sports Med. 2012;33(10):789-794; doi: 10.1055/s-00321304640

15. Faria EW, Parker DL, Faria IE. The science of cycling: factors affecting performance - part 2. Sports Med. 2005; 35(4):313-337; doi: 10.2165/00007256-20053504000003.

16. Lucía A, Hoyos J, Pérez M, Santalla A, Chicharro JL. Inverse relationship between $\mathrm{VO}_{2}$ max and economy/efficiency in world-class cyclists. Med Sci Sports Exerc. 
R. Hebisz, R. Blacha, P. Hebisz, S. Szczepan, Ability to repeat the given pressure force

2002;34(12):2079-2084; doi: 10.1249/01.MSS.00000 39306.92778.DF.

17. Hopker J, Coleman D, Passfield L. Changes in cycling efficiency during a competitive season. Med Sci Sports Exerc. 2009;41(4):912-919; doi: 10.1249/MSS.0b013e $31818 f 2 a b 2$.

18. Louis J, Hausswirth C, Easthope C, Brisswalter J. Strength training improves cycling efficiency in master endurance athletes. Eur J Appl Physiol. 2012;112(2): 631-640; doi: 10.1007/s00421-011-2013-1.

19. Whitty AG, Murphy AJ, Coutts AJ, Watsford ML. The effect of low- vs high-cadence interval training on the freely chosen cadence and performance in endurancetrained cyclists. Appl Physiol Nutr Metab. 2016;41(6): 666-673; doi: 10.1139/apnm-2015-0562.

20. Horowitz JF, Sidossis LS, Coyle EF. High efficiency of type I muscle fibers improves performance. Int J Sports Med. 1994;15(3):152-157; doi: 10.1055/s-2007-1021038.

21. Majerczak J, Szkutnik Z, Karasinski J, Duda K, Kolodziejski L, Zoladz JA. High content of MYHC II in vastus lateralis is accompanied by higher $\mathrm{VO}_{2}$ /power output ratio during moderate intensity cycling performed both at low and at high pedalling rates. J Physiol Pharmacol. 2006;57(2):199-215.

22. Chavarren J, Calbet JA. Cycling efficiency and pedalling frequency in road cyclists. Eur J Appl Physiol Occup Physiol. 1999;80(6):555-563; doi: 10.1007/s0042100 50634.

23. Coyle EF, Sidossis LS, Horowitz JF, Beltz JD. Cycling efficiency is related to the percentage of type I muscle fibers. Med Sci Sports Exerc. 1992;24(7):782-788; doi: 10.1249/00005768-199207000-00008.

24. Lucia A, San Juan AF, Montilla M, CaNete S, Santalla A, Earnest C, et al. In professional road cyclists, low pedaling cadences are less efficient. Med Sci Sports Exerc. 2004;36(6):1048-1054; doi: 10.1249/01.MSS. 0000128249.10305.8A.

25. Hilt PM, Berret B, Papaxanthis C, Stapley PJ, Pozzo T. Evidence for subjective values guiding posture and movement coordination in a free-endpoint whole-body reaching task. Sci Rep. 2016;6:23868; doi: 10.1038/srep 23868.

26. Blake OM, Champoux Y, Wakeling JM. Muscle coordination patterns for efficient cycling. Med Sci Sports Exerc. 2012;44(5):926-938; doi: 10.1249/MSS.0b013 e3182404d4b.

27. Mornieux G, Gollhofer A, Stapelfeldt B. Muscle coordination while pulling up during cycling. Int J Sports Med. 2010;31(12):843-846; doi: 10.1055/s-0030-1263140.

28. Thomas AG, Dennis A, Bandettini PA, JohansenBerg H. The effects of aerobic activity on brain structure. Front Psychol. 2012;3:86; doi: 10.3389/fpsyg. 2012. 00086.

29. Błacha R. Repeatability of isometric muscle tension as a way to measure kinesthetic differentiation ability [in Polish]. Wrocław: AWF; 2013.

30. Mustafa K, Furmanek MP, Knapik A, Bacik B, Juras G. The impact of the Swedish massage on the kinesthetic differentiation in healthy individuals. Int J Ther Massage Bodywork. 2015;8(1):2-11; doi: 10.3822/ijtmb. v8i1.252.

31. Zatoń M, Błacha R, Jastrzębska A, Słonina K. Repeatability of pressure force during elbow flexion and extension before and after exercise. Hum Mov. 2009;10(2): 137-143; doi: 10.2478/v10038-009-0010-6.

32. Zaton M, Błacha R. The method of measuring the pressure of human limbs and the device for measuring the pressure of human limbs [in Polish]. Biuletyn Urzędu Patentowego. 2008;16:4.

33. Thomas JR, Nelson JK, Silverman SJ. Research methods in physical activity, $7^{\text {th }}$ ed. Champaign: Human Kinetics; 2015.

34. Adamo DE, Alexander NB, Brown SH. The influence of age and physical activity on upper limb proprioceptive ability. J Aging Phys Act. 2009;17(3):272-293; doi: 10.1123/japa.17.3.272.

35. Iwasaki S, Kaiho T, Iseki K. Handedness trends across age groups in a Japanese sample of 2316. Percept Mot Skills. 1995;80(3 Pt 1):979-994; doi: 10.2466/pms. 1995.80.3.979.

36. Mutha PK, Haaland KY, Sainburg RL. The effects of brain lateralization on motor control and adaptation. J Mot Behav. 2012;44(6):455-469; doi: 10.1080/ 00222895.2012 .747482 .

37. Han J, Waddington G, Adams R, Anson J. Bimanual proprioceptive performance differs for right- and lefthanded individuals. Neurosci Lett. 2013;542:37-41; doi: 10.1016/j.neulet.2013.03.020.

38. Goble DJ, Brown SH. Upper limb asymmetries in the perception of proprioceptively determined dynamic position sense. J Exp Psychol Hum Percept Perform. 2010; 36(3):768-775; doi: 10.1037/a0018392.

39. Hills AP, Mokhtar N, Byrne NM. Assessment of physical activity and energy expenditure: an overview of objective measures. Front Nutr. 2014;1:5; doi: 10.3389/fnut. 2014.00005.

40. Haakonssen EC, Martin DT, Burke LM, Jenkins DG. Energy expenditure of constant- and variable-intensity cycling: power meter estimates. Med Sci Sports Exerc. 2013;45(9):1833-1840; doi: 10.1249/MSS.0b013e31 828e18e6.

41. Keytel LR, Goedecke JH, Noakes TD, Hiiloskorpi H, Laukkanen R, van der Merwe L, et al. Prediction of energy expenditure from heart rate monitoring during submaximal exercise. J Sports Sci. 2005;23(3):289297; doi: 10.1080/02640410470001730089.

42. Sone R, Tan N, Nishiyasu T, Yamazaki F. Autonomic heart rate regulation during mild dynamic exercise in humans: insights from respiratory sinus arrhythmia. Jpn J Physiol. 2004;54(3):273-284; doi: 10.2170/jjphysiol.54.273.

43. Bhambhani Y, Norris S, Bell G. Prediction of stroke volume from oxygen pulse measurements in untrained and trained men. Can J Appl Physiol. 1994;19(1):49-59; doi: 10.1139/h94-003. 